\title{
Role of artificial intelligence in smart grids
}

\author{
Ahmet Onen ${ }^{1}$ \\ Published online: 9 November 2021 \\ (c) The Author(s), under exclusive licence to Springer-Verlag GmbH Germany, part of Springer Nature 2021
}

This special issue of Electrical Engineering-Archiv fur Elektrotechnik is oriented on the emerging trends of electrical engineering with particular reference to Artificial Intelligence (AI) and trends applied in power systems.

The papers are contributing to challenges and opportunities from increasing penetration of renewables, digitalization, hybrid operation of AC and DC grids, and aging infrastructure as providing $\mathrm{AI}$ is one of the great solutions of these. The papers collected in this special issue show that current trends are defined by the rise of studies in the field of artificial intelligent application on power system. In particular, AI architecture and trends are used in power systems, machine learning algorithms in smart grids, blockchain integrated AI-based solutions in electrical power system applications, batteriesbased solution with AI, artificial intelligence applied to power system optimization, optimized management in microgrids and energy hubs, AI-driven solutions for the next generation of the smart-grid, decentralization and digitalization in smart grids, data analytics for electrical energy systems.
Let us thank the authors, colleagues, reviewers, and those who contributed and prepared this issue of the journal of Electrical Engineering-Archiv fur Elektrotechnik.

On behalf of the guest editorial board (Ahmet Onen, Shiping Wen, Taha Selim Ustun, Zhiwei Liu).

Publisher's Note Springer Nature remains neutral with regard to jurisdictional claims in published maps and institutional affiliations.

$\triangle$ Ahmet Onen

a.onen@squ.edu.om

1 Department of Electrical and Computer Engineering, College of Engineering, Sultan Qaboos University, Al-Khoud, Muscat 123, Oman 